\title{
Hydrocephalus Revealed by Relapsing Bilateral Fourth Cranial Nerve Palsy
}

\author{
Loïc Moens $\mathrm{MD}^{1 *}$, Antonella Boschi MD¹, Thierry Duprez MD², Jose-Geraldo Ribeiro-Vaz MD³ \\ ${ }^{l}$ Departement of Ophtalmology, Université Catholique de Louvain UCL, Brussels, Belgium. \\ ${ }^{2}$ Departement of Neuroradiology, Université Catholique de Louvain UCL, Brussels, Belgium. \\ ${ }^{3}$ Departement of Neurosurgery, Université Catholique de Louvain UCL, Brussels, Belgium.
}

\begin{abstract}
Introduction: Uni- or bi-lateral fourth cranial nerve palsy due to hydrocephalus and/or after VPS placement is a very rare oculomotor manifestation. We report a case of relapsing bilateral fourth nerve palsies demonstrating recurring hydrocephalus. We reviewed the literature (table1) in order to inform the clinician about the clinical assessment, the past medical history and the radiological findings that prompt research for this peculiar entity and to avoid misdiagnoses like palsies of the sixth cranial nerve.

Diagnosis, intervention and outcome: The patient presented with recurrence of diplopia in reading position, partially resolved after a second VPS placement. A diagnosis of bilateral fourth nerves palsies was done after complete neuroophthalmological evaluation. A close follow-up demonstrated fluctuating level of diplopia by changing VPS valve resistance. An optimal placement of the VPS offered reduction and stability of diplopia. A final strabismus surgery was necessary to obtain complete symptoms release.
\end{abstract}

\section{KEYWORDS}

Hydrocephalus, Isolated fourth ventricle hydrocephalus, Fourth nerve palsy, Strabismus.

Correspondins Author Information

Loïc Moens, MD

Université Catholique de Louvain UCL Brussels, neuro-ophtalmology service, Departement of ophthalmology. Address Avenue Lambeau 29,1200 Brussels, Tel. +32 4715147 07; E-mail: loic.moens@uclouvain.be; ORCID identifier: 0000-0002-8909-241X.

Received: November 05, 2020; Accepted: November 29, 2020; Published: December 06, 2020

Copyright: (C) 2020 ASRJS. This is an openaccess article distributed under the terms of the Creative Commons Attribution 4.0 International license.

Citation: Loïc Moens, Antonella Boschi, Thierry Duprez, Jose-Geraldo Ribeiro-Vaz. Hydrocephalus Revealed by Relapsing Bilateral Fourth Cranial Nerve Palsy. Med Clin Res Open Access. 2020;1(1):1-3.

\section{Case Description}

We report the case of a healthy 48-years-old woman presenting with a few-month history of headache, diplopia in reading position and nausea. Tetra ventricular hydrocephalus had been shown at MRI at early phase of the disease course and a prominent enlargement of the fourth ventricle had been highlighted. The first brain imagery shows a tetra ventricular hydrocephalus with a particularly enlarged fourth ventricle. As a strong flow artifact was observed through the aqueduct of Sylvius (Figure 1), a subocclusion of the foramina of Magendie and Luschka together with a lower grade stenosis of the aqueduct had been hypothesized. A ventriculoperitoneal shunting (VPS) of the right lateral ventricle with a Medtronic Adjustable Strata Regular ${ }^{\circledR}$ II valve with Delta siphon control device was subsequently performed in another institution with 2.0 opening pressure. Diplopia persisted and dysfunction of the system was diagnosed in our institution. 


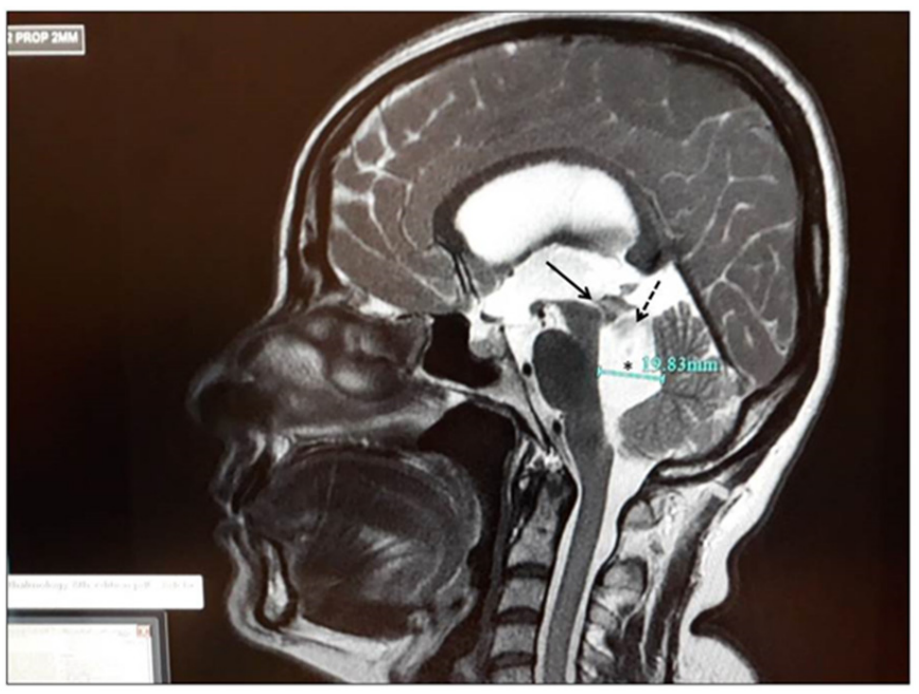

Figure 1: Mid-sagittal T2-weighted MR view showing elective over dilatation of the fourth ventricle together with enhanced flow artifact through the aqueduct of Sylvius (arrow) and at upper part of the ventricle (dotted arrow).

The shunt system was changed and we decided to set valveopening pressure to 1.5 (standing opening pressure $8.5 \mathrm{~cm}$ $\mathrm{H}_{2} \mathrm{O}$ ). After a month period of symptoms relief, a recurrence of morning headaches with oblique diplopia occurred. An isolated bilateral fourth cranial nerve palsy was assessed considering the features of: i: subjective exyclotorsion over $10^{\circ}$; ii: V syndrome;

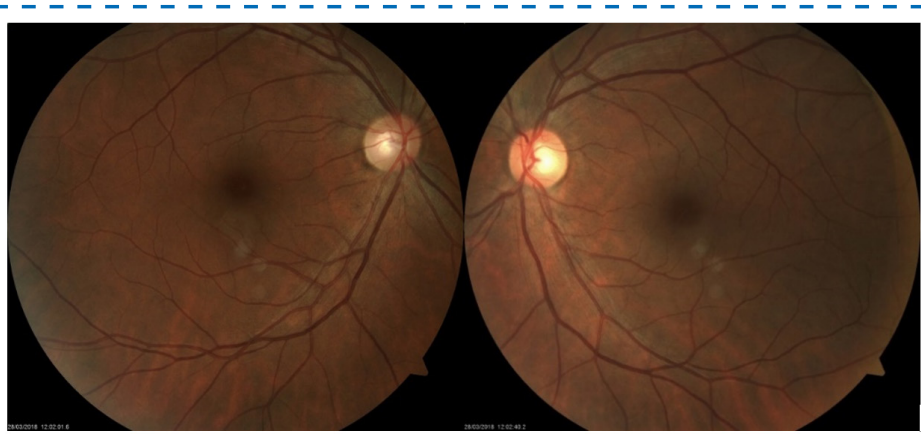

Figure 2: Funduscopy of our patient showing bilateral exyclotorsion.

iii: hypertropia increased in tilting positions, and iii: bilateral exyclotorsion at the fundus examination (Figure 2). Downgrading of the resistance of the Strata valve resulted in symptoms subsidence for only a few days. Though RMI control was unremarkable, an intermittent dysfunction of the ventriculoperitoneal shunting was strongly suspected considering relapses of similar episodes of oculomotor disturbance. VPS was therefore replaced (with a maintained opening pressure of 1.5) resulting in a one-year period of stabilization of the diplopia.

\section{Follow up and outcome}

After replacement of the changed VPS in our institution, a close follow up over one year highlighted stable reduction of diplopia without complete resolution. Surgical correction of the strabismus

\begin{tabular}{|c|c|c|c|c|c|c|}
\hline $\begin{array}{l}\text { Authors of the } \\
\text { case report }\end{array}$ & $\begin{array}{l}\text { Description of the } \\
\text { patient and onset } \\
\text { of complains }\end{array}$ & $\begin{array}{l}\text { Etiology of the } \\
\text { hydrocephalus }\end{array}$ & $\begin{array}{c}\text { Side } \\
\text { affected }\end{array}$ & MRI findings & Treatment & Outcome \\
\hline $\begin{array}{l}\text { [1] Dimosthenis } \\
\text { Mantopoulos, } \\
\text { David G Hunter, } \\
\text { Dean M.Cestari }\end{array}$ & $\begin{array}{c}29 \text { yo man } \\
\text { Vertical diplopia } \\
\text { worse in down } \\
\text { gaze } 10 \text { Y after } \\
\text { shunting }\end{array}$ & $\begin{array}{c}\text { Initial VPS placement } \\
\text { for subarachnoid } \\
\text { hemorrhage years } \\
\text { before }\end{array}$ & Bilateral & $\begin{array}{c}\text { Discovery of a } \\
\text { dysfunctional VPS in } \\
\text { good position with a } \\
\text { broad enlarged third and } \\
\text { fourth ventricle }\end{array}$ & $\begin{array}{l}\text { New } \\
\text { ventriculostomy of } \\
\text { the third ventricle }\end{array}$ & $\begin{array}{l}\text { Spontaneous } \\
\text { resolving of diplopia }\end{array}$ \\
\hline $\begin{array}{c}{[2 \mathrm{~A}] \text { Pandey PK, }} \\
\text { et al. }\end{array}$ & $\begin{array}{c}20 \text { yo woman } \\
\text { vertical diplopia } \\
\text { immediately after } \\
\text { shunting }\end{array}$ & $\begin{array}{l}\text { VPS placement for } \\
\text { tubercular meningitis }\end{array}$ & Unilateral & $\begin{array}{l}\text { Discovery of functioning } \\
\text { VPS in good position. } \\
\text { Good sized ventricles. }\end{array}$ & $\begin{array}{l}\text { Strabismus surgery } \\
\text { by } 6 \mathrm{~mm} \text { left } \\
\text { inferior oblique } \\
\text { recession }\end{array}$ & Diplopia disappeared \\
\hline $\begin{array}{c}\text { [2B] Pandey PK, } \\
\text { et al. }\end{array}$ & $\begin{array}{c}16 \text { yo boy } \\
\text { vertical diplopia } \\
\text { immediately after } \\
\text { shunting }\end{array}$ & $\begin{array}{l}\text { VPS placement for } \\
\text { solitary pontine } \\
\text { tuberculoma }\end{array}$ & Unilateral & $\begin{array}{l}\text { Discovery of functioning } \\
\text { VPS in good position. } \\
\text { Good sized ventricles. }\end{array}$ & $\begin{array}{l}\text { Strabismus surgery } \\
\text { by } 6 \mathrm{~mm} \text { left } \\
\text { inferior oblique } \\
\text { recession }\end{array}$ & Diplopia disappeared \\
\hline $\begin{array}{l}\text { [3] Giesemann } \\
\text { AM,et al. }\end{array}$ & $\begin{array}{l}82 \text { yo man } \\
\text { Complains of } \\
\text { vertical diplopia } \\
\text { after VPS }\end{array}$ & $\begin{array}{l}\text { Non obstructive } \\
\text { chronic } \\
\text { hydrocephalus }\end{array}$ & Bilateral & $\begin{array}{l}\text { Complication of the } \\
\text { surgery with trauma of } \\
\text { the pretectum }\end{array}$ & Surveillance & Diplopia persists \\
\hline Our case & 48 yo lady & $\begin{array}{c}\text { Intermittent } \\
\text { malfunction of the } \\
\text { ventriculoperitoneal } \\
\text { shunt was } \\
\text { hypothesized }\end{array}$ & Bilateral & $\begin{array}{l}\text { Discovery of a functional } \\
\text { VPS in good position } \\
\text { with a tetra ventricular } \\
\text { hydrocephalus and } \\
\text { particularly enlarged } \\
\text { fourth ventricle }\end{array}$ & $\begin{array}{l}\text { VPS replacement } \\
\text { Strabismus } \\
\text { and strata II } \\
\text { valve resistance } \\
\text { adaptation } \\
\text { followed by } \\
\text { surgery after 1 year }\end{array}$ & $\begin{array}{l}\text { Diplopia fluctuated } \\
\text { with Strata II } \\
\text { valve resistance till } \\
\text { stabilization } \\
\text { And diplopia resolved } \\
\text { after strabismus } \\
\text { surgery }\end{array}$ \\
\hline
\end{tabular}

Table 1: Review in the literature of cases of isolated fourth nerve palsies as unique sign of hydrocephalus. 
by a Harada-Ito procedure on the right eye had thereafter an excellent functional outcome with complete subsidence of the symptoms.

\section{Discussion}

Based on a thorough review of the literature, IV nerve palsies due to cerebro-spinal fluid (CSF) flow dysfunction has been scarcely reported [Table 1].

Hydrocephalus is defined as a disturbance of the flow of cerebrospinal fluid that leads to an increase in volume occupied by this fluid in CNS. So-called 'Communicating' hydrocephalus is featured by a disturbance of the CSF resorption in arachnoid villi leading to increased fluid volume within an unexpandable CNS without obstacle throughout the CSF pathways. In turn, the "noncommunicating' hydrocephalus either is featured by a detectable obstacle along CSF pathways within ventricles or occurs within the foramina impairing the outflow of ventricular CSF in the subarachnoid spaces. A peculiar sub-entity of the latter condition is the fourth ventricle hydrocephaly where there is the elective or preferential enlargement of the fourth ventricle. This entity of hydrocephalus has been reported as a complication of spontaneous or iatrogenic intraventricular hemorrhage, meningitis, or because of chronically excessive drainage by the VPS [4].

Most frequent ophthalmological signs of hydrocephalus are papilledema, enlarged blind spot at the perimetry, failure of upward gaze and unilateral or bilateral VI nerve palsy. In turn, as seen with our patient, fourth nerve palsy gives an oblique double vision increasing in down gazes and in the tilting positions (Bielschowsky test). The main differential diagnostic for these symptoms is the skew deviation. The exyclotorsion of the affected eye and the three steps method is usually conclusive in distinguishing the two entities (Figure 2).

Uni- or bi-lateral IV nerve palsy due to hydrocephalus and/or after VPS placement is a very rare oculomotor manifestation. The mechanism hypothesized in the literature [4] is either a stretching of the IV nerve resulting from an impingement of the superior medullary velum or a shearing of the midbrain due to the enlargement of the fourth ventricle. Since the cerebellar hemispheres are fixed by adhesions to the dura, the sole structure able to move in such mechanically constraining condition is the brainstem. In our patient all ventricles were enlarged since the initial phase of the disease course, but with a prominent enlargement of the fourth ventricle. The aperture pressure at lumbar puncture was normal which suggests significant obstruction of Magendie's and Luschka's foramina together with lower grade stenosis of the aqueduct of Sylvius. In the frame, we also noticed signs of CSF per-ependymal transudation in brain parenchyma surrounding the foramina. CSF analyses were normal. After thorough electronic review of the literature, only four cases of fourth nerve palsy in patients with hydrocephalus have been reported up to now [Table 1] who had all radiological/clinical features matching our hypothesis of preferentially elevated CSF pressure within the fourth ventricle. Furthermore, as CSF pressure fluctuates in hydrocephalus because of variable imbalance between CSF production and resorption, the diplopia fluctuated and the fluctuations closely matched changes in the resistance of the adjustable VPS valve. This observation strongly supported the hypothesis of CSF pressure-related changes in IV nerve dysfunction.

\section{Conclusion}

In conclusion, occurrence of diplopia enhancing in reading position or descending the stairs in a patient with history of hydrocephalus should suggest a uni- or bi-lateral IV nerve palsy, mainly in cases in whom overdilatation of the fourth ventricle when compared to other ventricles is assessed at CT or MR brain imaging. Risk factors such as previous VPS placement or meningitidis must be asked for. We advocate the proposal of a neuro-ophthalmology examination in all patients with hydrocephalus and diplopia to better define the oculomotor dysfunction, to establish the possible relationship between those entities and to improve the clinical follow up before or after VPS placement.

\section{References}

1. Mantopoulos D, Hunter DG, Cestari DM. Isolated bilateral fourth nerve palsies as the presenting sign of hydrocephalus. Case Reports in Ophtalmology.2011 May-Aug; 2(2): 211-214.

2. Pandey PK, Dadeya S, Amar A et al. Acquired isolated unilateral fourth nerve palsy after ventriculoperitoneal shunt surgery. American Association for Pediatric Ophtalmology and Strabismus. May 2008; 12(6):618-620.

3. Giesemann AM, Capelle HH, Winter $\mathrm{R}$ et al. Bilateral trochlear nerve palsy subsequent to ventriculoperitoneal shunting of normal pressure hydrocephalus. British Journal of Neurosurgery. May 2011; 26(1):110-112.

4. Khalid A, Ravindra N, Khalid H. The isolated fourth ventricle. BMJ Publishing Group. April 2013. 